\title{
Article
}

\section{Salvaging Truth from Ontological Scrap}

\author{
Cornell, David Michael
}

Available at http://clok.uclan.ac.uk/36935/

Cornell, David Michael ORCID: 0000-0002-6980-8804 (2021) Salvaging Truth from Ontological Scrap. Philosophy . ISSN 0031-8191

It is advisable to refer to the publisher's version if you intend to cite from the work. http://dx.doi.org/10.1017/S0031819121000048

For more information about UCLan's research in this area go to

http://www.uclan.ac.uk/researchgroups/ and search for < name of research Group>.

For information about Research generally at UCLan please go to http://www.uclan.ac.uk/research/

All outputs in CLoK are protected by Intellectual Property Rights law, including Copyright law. Copyright, IPR and Moral Rights for the works on this site are retained by the individual authors and/or other copyright owners. Terms and conditions for use of this material are defined in the policies page.

\section{CLoK}

Central Lancashire online Knowledge www.clok.uclan.ac.uk

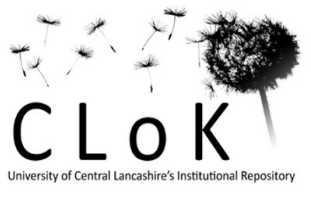




\title{
Salvaging Truth from Ontological Scrap
}

\author{
David M. Cornell
}

\begin{abstract}
What should one do when one's philosophical conclusions run counter to common sense? Bow to the might of ordinary opinion or follow the indiscriminate force of philosophical reason, no matter where it leads? A few strategies have recently been proposed which suggest we needn't have to make this difficult choice at all. According to these views, we can accept the truths of common sense whilst simultaneously endorsing philosophical views with which they seem to conflict. We can, for instance, accept it as true that the Taj Mahal is in India, whilst also eliminating the Taj Mahal from our ontology. I argue that these strategies generate a new conflict with common sense and thus undercut one of the central motivations that drives them. I also argue for the stronger claim that these kinds of 'truth-salvaging' strategy are incapable in principle of reconciling theory with common sense. This does not mean that they must be abandoned, for there may be good independent reasons for endorsing them, but it does eliminate one of their most promising advantages. The upshot of the paper will be twofold. First, one of the major motivations for endorsing these kinds of strategy will be severely undermined. Secondly, and perhaps more significantly, it will mean that for those who think philosophy should be strictly constrained by common sense, all radical ontological views will effectively be off the table.
\end{abstract}

\section{§1. Introduction}

Bertrand Russell once said that 'the point of philosophy is to start with something so simple as not to seem worth stating, and to end with something so paradoxical that no one will believe it' (Russell, 1972, p.20). I think Russell may have been overstating it a little in suggesting that this was the point of philosophy, but it undeniably seems to be a common feature of philosophy. Anyone who has ever engaged in any serious philosophical reflection will have soon come to realise that the beliefs we take for granted can often generate seemingly absurd or paradoxical consequences.

This has led many philosophers to endorse some rather fantastical conclusions. Parmenides is said to have believed that nothing ever changes, for instance, whilst Heraclitus claimed that nothing ever stays the same. Much later, McTaggart denied the reality of time, not that long after Hume had denied the existence of the self. The trend continues today, with a particularly 
popular form of intellectual insurrection currently being the denial of ordinary material objects, such as tables, cars, houses, and planets. ${ }^{1}$ Some philosophers even deny the existence of human beings. Indeed, for evidence of such radical thinking in philosophy, one surely needs to look no further than Peter Unger's provocatively titled paper, 'I Do Not Exist' (Unger, 1979).

These radical views bring with them an important and perennial question: what ought one to do when one's philosophical conclusions conflict with common sense? Two avenues of response present themselves immediately. One would be to stick to your guns, have faith in your philosophical reasoning, and denounce common sense if it comes down to it. ${ }^{2}$ The other would be to succumb to the authority of common sense and to alter one's philosophical beliefs accordingly. ${ }^{3}$ But there is a third option which has been making considerable ground in recent years, according to which we can enjoy the best of both worlds. Advocates of this third option claim that we can maintain conviction in our radical philosophical conclusions yet also hang on to the literal truth of the commonsense beliefs with which they seem to conflict. In the same breath that they reject the existence of planets, for instance, they happily accept it as true that there are eight planets in the solar system. On the back of their philosophical reasoning they readily consign ordinary objects to the ontological scrapheap, safe in the knowledge that they can salvage the truth of our ordinary assertions about such things. These philosophers, it seems, believe we can have our cake and eat it. ${ }^{4}$

It is this third approach to the question - which I will call the truth-salvaging approach - that is the subject of this paper. There is an obvious attraction to this kind of strategy, for if it is successful, it effectively frees one's metaphysics from many of the constraints of common sense. It allows one to follow one's philosophical reasoning to its logical conclusions, no matter what they might be, whilst all the while knowing that the truths of common sense remain unscathed. Nice work if you can get it.

I will argue that these kinds of strategy fail in their aim to reconcile radical ontology with common sense and, in so doing, they undercut one of the central motivations that drives them

\footnotetext{
${ }^{1}$ I include myself in this merry band of ordinary-object-deniers but will not be arguing for the position here. For defences of this view, see van Inwagen (1990), Merricks (2001), Cameron (2010a), Sider (2013), Cornell (2017).

${ }^{2}$ This is the Parmenidean route; a route still well-travelled, as Peter Unger demonstrates. This kind of view is normally accompanied by some kind of explanation of why common sense has gone so wrong. See, for instance, Trenton Merricks' claim that many commonsense beliefs are, although false, "nearly as good as true", (Merricks, 2001, p.165).

${ }^{3}$ G. E. Moore would probably be the obvious example here. More recently, Schaffer (2009) has adopted this kind of stance.

${ }^{4}$ I will be focusing specifically on the work of Cameron (2008a; 2008b; 2010a) and Horgan \& Potrč (2000; 2006; 2008), but there are others who endorse similar kinds of view too. See, for instance, Heil (2012), and Dorr (2008).
} 
in the first place. I will also argue for the stronger claim that strategies of this type seem incapable in principle of reconciling theory with common sense. This does not mean, of course, that views of this type are all doomed to failure, for there may well be other ways of motivating them and independent reasons to endorse them. But I contend that if their ability to reconcile radical ontology with common sense is illusory, as I will argue that it is, they have lost one of their most promising advantages.

\section{§2. Setting up the Debate}

To set up the debate, I will focus on eliminativism about ordinary objects as a case study, since it is a much-debated view at present, as well as being a paradigmatic example of a philosophical view that clashes with common sense. Many philosophers endorse eliminativism and deny the existence of ordinary material objects (tables, cars, planets, etc.) for a variety of different reasons. ${ }^{5}$ Eliminativism seems to lead directly to a major conflict with common sense because it appears to be incompatible with all sorts of commonsense claims, such as:

(1): There is a table in my dining room

(2): There are three cars parked on the street

(3): There are eight planets in the solar system

The conflict is evident. How could (1), (2), and (3) possibly be true if there are no tables, cars, or planets?

Before looking at the strategies which are the central focus of this paper, it should be worthwhile to say something briefly about the more standard approach to this type of conflict: paraphrase. Ever since Quine it has been common in philosophy to get around apparent conflicts between the things we ordinarily believe and the things our theories suggest by providing paraphrases of the former that are consistent with the latter. Thus if theory suggests that there are no tables but just elementary particles, for instance, the apparent conflict with common sense can be mitigated by highlighting the fact that whilst the statement, 'there are

\footnotetext{
${ }^{5}$ See, for instance, Sider (2013), Horgan \& Potrč (2000; 2008), Cameron (2010a), Dorr (2005). One should not forget, however, that despite the fact these papers are very recent, the view itself is quite ancient. In the west, it can be traced back at least as far as Democritus, who famously claimed that reality was nothing but atoms and void. But it also has a long history in Indian thought. See Siderits (2019), for instance, for an interesting reconstruction of an ancient Buddhist argument for eliminativism.
} 
tables' is false, the statement that 'there are particles arranged table-wise' is true. ${ }^{6}$ The truth of the paraphrase is taken to justify the offending commonsense assertion that there are tables.

Paraphrase strategies tend to fall into one of two camps. To borrow some terminology from John Keller, there are 'revisionary' approaches and 'reconciliatory' approaches (Keller, 2015). The former approach takes the offending commonsense assertions to be literally false, but maintains that in light of the appropriate paraphrases, they are nonetheless justified or warranted. ${ }^{7}$ The thought underlying this view, it seems, is that there are different varieties of falsehood. For instance:

(1) The sun moves across the sky each day.

(2) The sun is made of cheese.

Both statements are, strictly speaking, false. ${ }^{8}$ Nonetheless, statement (1) gets at least something right. There is a clear sense in which (1) corresponds with the facts in an important and relevant way. It is merely a misleading characterisation of the true fact of the matter - a fact that can be accurately captured by a relevant paraphrase (e.g. 'the regular rotation of the Earth makes it appear as though the sun moves across the sky each day' or something along those lines). Thus the existence of the true and relevant paraphrase would justify someone in uttering (1), even though it is strictly false.

Assertion (2) is different. It does not correspond with the facts in any relevant way. It is wildly off the mark, and there is no true paraphrase of this claim in the relevant vicinity that could justify its assertion. Both assertions are false, therefore, yet (1) is warranted and (2) is not, or so the thought goes. The same kind of reasoning, it is claimed, can be applied in the case of ordinary material objects. It may be false, strictly speaking, to say that 'there is a table in the room', but this is merely a misleading characterisation of the true fact of the matter; a fact which is better captured by the true paraphrase, 'there are particles arranged table-wise in the room'. Correspondingly, it would also be false to state 'there is a unicorn in the room'. But this would not be warranted, since such an assertion would be wildly off the mark, not merely a misleading characterisation of the facts. ${ }^{9}$

The latter approach - the reconciliatory approach - takes the offending assertions to be literally true, but only by insisting that they express, albeit in a roundabout and misleading

\footnotetext{
${ }^{6}$ Van Inwagen (1990) is the classic example of this approach, and the locution "arranged x-wise" is his. ${ }^{7}$ This is the approach taken by Merricks (2001). Van Inwagen is normally taken to adopt this view too, but it is not always entirely clear. In some places he seems to suggest that the offending commonsense assertions are literally true, which would place him in the reconciliatory camp.

${ }^{8}$ (1) is false, of course, because as Copernicus taught us, the sun is stationary - it does not move at all. It is we who move around the sun, not the sun that moves around us. This example is a variation of that given by van Inwagen (1990).

${ }_{9}^{9}$ Providing, of course, that there are no particles arranged unicorn-wise in the room.
} 
way, the true proposition that is more accurately captured by the relevant paraphrase. Thus when one asserts 'there is a table in the living room', what one really means is more perspicuously expressed by the paraphrase, 'there are some particles arranged table-wise in the living room'. Whilst these strategies may have their merits, I will not be considering them here because they are, I think, importantly different from the strategies I wish to focus on. The main reason for this is that whilst these paraphrase strategies go some way towards bridging the gap between theory and common sense, they fall some way short of bridging it completely. This is quite clear with the revisionary approach; it denounces our commonsense claims as false, and simply provides an explanation of why we are justified in believing such falsehoods. But a falsehood is a falsehood all the same, thus the revisionary approach fails to salvage the truths of common sense. The reconciliatory approach fails too, I would suggest, for whilst it may allow that our commonsense assertions are often true, it does so only at the expense of altering their meaning. This seems far from a genuine reconciliation, for it is of scant value to be told that one's assertions are true, if one is also told that they do not mean what one takes them to mean. ${ }^{10}$

The strategies I wish to focus on, of which a few have been proposed over recent years, are distinct from the above paraphrase strategies in that they claim to dissolve the conflict between radical ontology and common sense in its entirety. That is, they claim to preserve not only the literal truth of our commonsense assertions, but also their literal meaning, despite the fact that they seem to conflict with our ontological theories. I have labelled these 'truthsalvaging strategies' for the fairly obvious reason that they claim to salvage the truths of common sense from the harsh realities of philosophical reflection. I will focus on two truthsalvaging strategies in particular.

The first, which I shall call 'The Truthmaker Strategy', has been defended by Ross Cameron and John Heil, and embraces the truthmaker principle ${ }^{11}$ :

(TP): For every true proposition, $p$, there exists at least one entity which makes $p$ true. ${ }^{12}$

\footnotetext{
${ }^{10}$ I think there are evident similarities between these reconciliatory paraphrase strategies and the truthsalvaging strategies I will be discussing in what follows. These similarities should become clear as the paper progresses. If these similarities are close enough, then perhaps the criticisms I offer against the truth-salvaging strategies will also apply to the reconciliatory paraphrase strategies. I will leave it as an open question as to just how similar the strategies are.

${ }^{11}$ Cameron (2008a; 2008b; 2010a) and Heil (2003; 2012). Cameron explicitly acknowledges that his view was inspired by Heil's work.

${ }^{12}$ This is a somewhat loose definition, since there is scope for much disagreement over how to understand the phrase, 'makes $p$ true'. But it gets the general gist of the principle across in a way sufficient for present purposes. See Beebee \& Dodd (2005) for a more detailed discussion of how best to formulate the truthmaker principle. Also, see Armstrong (2004) for a classic exposition and defence of truthmaking.
} 
However, this rather standard formulation of the truthmaker principle is then supplemented with the distinctly less-standard claim that the truthmakers for a particular proposition, $p$, needn't include the entities to which $p$ purportedly refers. That is, the truthmakers for a sentence of the form, ' $a$ exists' needn't include $a$. Thus it could be quite true to say, 'the Taj Mahal exists' - i.e. strictly and literally true - even if there is no such thing as the Taj Mahal.

On first inspection, such a view looks as though it might lead straight to contradiction - for how could it possibly be true that the Taj Mahal exists if the Taj Mahal doesn't exist? But the view is more subtle than that. To see how, consider the following example from John Heil:

'Take three matches and arrange them so as to form a triangle. The triangle - the truthmaker for "this is a triangle" - is these matches in this arrangement. You do not have the matches, with their properties, so arranged, plus a triangle and its properties. What goes for the triangle goes for the individual matches as well. You do not have these particles, with their properties, duly arranged, plus the matches and their properties' (Heil, 2012, p.7).

The point is that the only things that really exist here are the simple particles and their properties, arranged in particular ways. But these particles act as truthmakers for an impressive array of propositions including, for instance, 'there are three matches' and 'there is a triangle'. These propositions are strictly and literally true, but their truth does not ontologically commit one to matches and triangles. The correct ontology need only contain the simple particles, arranged in the appropriate way. ${ }^{13}$

This is how the truthmaker strategist attempts to have her cake and eat it. She can maintain conviction in a sparse and radical ontology which contains nothing but simple particles and their properties, yet at the same time she can speak freely and truly about ordinary composite objects, like matches, triangles, and the Taj Mahal. ${ }^{14}$

The second strategy, which I will call, 'The Indirect Correspondence Strategy', is quite distinct from the Truthmaker Strategy but nonetheless has a similar upshot. It has been proposed by Terry Horgan \& Matjaž Potrč alongside their defence of monism: the view that there is only a single material object in existence - the world (Horgan \& Potrč, 2000; 2008). As ontological views go, monism is about as radical as it gets, for not only does it deny the existence of

\footnotetext{
${ }^{13}$ It can seem a little odd to say that whilst the matches and the triangle exist, the only things that really exist are the particles, for it immediately suggests that there is some kind of distinction being made here between 'real existence' and plain old 'existence', when most of us don't ordinarily recognise such a division. Ultimately, I think it is this kind of distinction that lies at the heart of these strategies, and which also lies at the heart of my concerns about them. I will expand on this in the next section.

${ }^{14}$ I should note that this strategy does not entail the ontology I have just described (i.e. one that consists of simple particles and nothing else). Indeed, Heil does not commit to this ontological view at all (although Cameron does).
} 
ordinary material objects, but it also denies the existence of the fundamental particles of physics. ${ }^{15}$ Unperturbed, however, Horgan \& Potrč maintain that theirs 'is a position that accommodates both common sense and science quite well despite its radical ontological claims' (Horgan \& Potrč, 2000, p.249).

Horgan \& Potrč point out that an ordinary sentence such as, 'there are eight planets in the solar system', for example, will only require the existence of planets for its truth if we take truth to be a matter of direct correspondence with the world. But there is no obvious reason, they claim, why we should be so smitten with such a direct form of alethic correspondence. Sure, they concede that truth must track reality in some uniform and systematic way (otherwise any old sentence could be true, regardless of what the world was like), but it needn't have to track reality directly. Rather, they claim, truth could consist in indirect correspondence with reality.

To make sense of this, it may help to consider an intriguing thought-experiment they put forward. They ask us to imagine a world consisting entirely of 'gunkish, jello-ish, stuff' which, although spatially extended, is literally part-less (Horgan \& Potrč, 2008, pp.168-70). Moreover, we are asked to imagine that this world exhibits localised qualitative variation across its extension, with respect to things like colour, density, and what have you. ${ }^{16}$ It is quite hard, they contend, to know how best to describe such a world, that is, how to accurately describe the nature of its qualitative variegation. But one plausible way one might go about it, they suggest, would be to construct a language (or 'linguistic framework', to use their term) that uses nouns which purport to refer to discrete entities within the world, even though there are no such entities. For instance, in the case of dramatic variations in density within the jelloworld, one might choose to speak of it having 'lumps', or in cases of dramatic variations in colour, one might say that it has 'spots'.

On the face of it, 'lump' is a singular term which ought, ordinarily speaking, to be used to refer to a single object. But, of course, this jello-world contains no discrete objects to which we might be referring to, because, ex hyopothesi, it has no parts. The only object there is the world itself, and we are certainly not referring to the entire world when we use the term 'lump', because we specifically created the term in order to pick out a particular sub-region of the world. (Indeed, even the term 'sub-region' would seem to pick out a 'part' of the jello-world - monistic worlds are indeed difficult to describe).

\footnotetext{
${ }^{15}$ Although see Cornell (2016) for reasons to think that we should take monism seriously, despite its apparent absurdity.

${ }^{16}$ Some people tell me that they have difficulty in even conceiving of a material object that is spatially extended yet has no parts. Descartes, too, seemed to think that such a thing was beyond the realms of conception (Descartes, 1934, p.209). Unfortunately, since I don't suffer from such restrictions in my own imagination, I have no real solution to such a predicament.
} 
The point that Horgan \& Potrč are making is this. We would not be incorrect to say that the jello-world has 'lumps', even though there are in fact no things to which we refer when we do so. In fact, they claim that such a description of the jello-world would be strictly and literally true. The reason for this is that although there is nothing that directly corresponds to our use of the term 'lump' (i.e. there are no objects to act as referents of the term), the description does indirectly correspond to the qualitative nature of the world. That is, when we talk of 'lumps here' or 'spots there', our descriptions accurately track the qualitative variation that is exhibited at the world, even though there are no such things as lumps or spots.

Once understood, this idea of truth as indirect correspondence could be tacked on to all sorts of radical ontological views in order to make those views consistent with the truths of common sense. Indeed, we could even suppose, as do Horgan \& Potrč, that our own world is monistic, i.e. that it has no parts, yet exhibits rich qualitative variation. The fundamental idea is that we can use nouns and singular terms to describe the world, and we can speak truly when we do so, even if there are no objects in existence to act as referents of those terms. What determines whether our descriptions are true is not whether or not the purported referents of the terms exist, but whether our descriptions accurately (albeit indirectly) track the qualitative nature of the world. As such, Horgan \& Potrč's view, just like the truthmaker strategy, can allow them to enjoy the best of both worlds. They can endorse radical sounding ontological views if that is where their reasoning takes them, but they can avoid any conflicts with the language of common sense. For they can easily allow that 'there are eight planets in the solar system' is true - strictly and literally true - even if there aren't really any planets.

\section{§3. The Problem}

There is a lot that can be said in favour of these strategies. Both have been meticulously spelled out and carefully argued for. However, I contend that they both fail to fulfil one of their central ambitions: they do not concord with common sense. Moreover, if what I have to say is correct, it seems that any strategy which works on similar principles will be unable to claim conformity with common sense. The upshot will be two-fold. First, one of the major motivations for endorsing these kinds of strategy will be severely undermined. Secondly, and perhaps more significantly, it will mean that for those who think philosophy should be strictly constrained by common sense, all radical ontological views will effectively be off the table.

The strategies fail to adhere with common sense, I claim, because whilst they do align with some of our commonsense intuitions, they do so at the cost of violating many others. To borrow a metaphor from David Armstrong, they smooth out one bump in the carpet only for it to reappear on the other side of the room (Armstrong, 1989). For it is all very well being told 
that it is true that there are eight planets in the solar system, or that there are three cars parked on the street, for instance, but it is another thing entirely if you supplement that with the additional caveat that there aren't really any planets or cars. But that is precisely what these strategies do: they allow that ordinary utterances about Fs can be strictly and literally true, but then with a nudge and a wink remind you that there aren't really any Fs. What these strategies are guilty of, I would suggest, is giving with one hand whilst taking away with the other.

To emphasise the point, consider the following from Ross Cameron: 'The claim, then, is that complex objects exist but don't really exist: what really exists are simply the simples' (Cameron, 2008b, p.6). To explain this, Cameron states that to say $x$ really exists means that one is ontologically committed to $x$, whereas to say that $x$ merely exists but doesn't really exist, is to say that the sentence, ' $x$ exists' is true, but is made true by something other than $x$. Thus Cameron is drawing a distinction between existence and ontology: 'ontology isn't concerned with what there is - or at least, it shouldn't be, since that's not an ontological issue but a linguistic one; ontology should be concerned with what there really is' (Cameron, 2010b, p.16). Horgan \& Potrč make a similar claim, saying that their strategy of truth as indirect correspondence 'renders numerous commonsense claims true while denying that these claims are ontologically committed to their posits' (Horgan \& Potrč, 2008, p.87).

These kinds of claim may well be coherent - indeed, they may even be true - but they can hardly be said to conform with what we ordinarily believe. To illustrate, consider Terry, an ordinary layperson, who announces that, 'there are ten biscuits in the biscuit tin'. There can be little doubt that Terry would be somewhat incredulous if you were to insist that what he had said was false, on the grounds that there are no such things as biscuits nor biscuit tins. On the surface, therefore, if you managed to maintain an ontological theory devoid of biscuits and tins, yet one which still allowed that Terry's utterance is actually true, this looks like some kind of improvement. Yes, the ontology may be sparse, but at least you aren't undermining Terry's ordinary beliefs.

But this is all very superficial. For suppose you were to continue, 'Look, Terry, what you assert is true, strictly and literally true, but just remember, there aren't really any biscuits or biscuit tins'. It is wildly implausible to suppose that Terry's incredulity would somehow be tempered by this assertion. Rather, it is likely that he would be even more incredulous, and even more confused, than he was in the first place. ('But how could it possibly be true, if there aren't really any biscuits or biscuit tins?' one could envisage his lament). But if this is correct, then it suggests that far from reconciling these philosophical views with common sense, these strategies actually drive an even more substantial wedge between the two. 
The strategies in question aim to salvage the truth of ordinary commonsense beliefs by opening up a division between the way things are and the way things really are; they distinguish between what there is and what there really is. This division is characterised in different ways. Cameron, for instance, says that whilst the objects of common sense (tables, cars, and planets, etc.) may exist, they do not have 'real being' (Cameron, 2010a, p.250). Horgan \& Potrč express it differently: they accept that there are such things, but deny that they are 'genuine denizens of reality' (Horgan \& Potrč, 2008, p.171) or part of the true 'furniture of the world' (Horgan \& Potrč, 2008, p.72). The problem is, it doesn't seem to matter what terminology you use to express it, the simple fact of the matter is that common sense recognises no such division. Terry would not accept that there is a difference between the way things are and the way things really are; he makes no distinction between the things that exist and the things that are genuine denizens of reality. It is beyond the limits of credibility to suggest that he would accept the claim that whilst there are ten biscuits in the tin, those biscuits do not have 'real being'. When Terry asserts that there are ten biscuits in the biscuit tin, he means what he says: there really are ten biscuits in the biscuit tin.

Let me put it another way. Both strategies hinge on the claim that language ordinarily relates to the world in a less direct way than we might ordinarily think, such that claims which seem to refer to ordinary objects (e.g. 'there is a table in the living room') can be literally true even though there is in fact no corresponding referent. It is this metalinguistic move which enables us to cling on to the truths of common sense whilst also endorsing our preferred radical ontological view. The problem is, however, that this novel understanding of truth seems so far from the norm that one wonders if it is still worth clinging on to. Most people, I would imagine, would take very little solace in the knowledge that is true that there are tables, if at the same time they are made aware that there aren't really any tables.

It is perhaps worth saying something here by way of clarification. I am not suggesting that either Cameron or Horgan \& Potrc deny Tarki's T-schema (i.e. ' $p$ ' is true iff $p$ ), for they explicitly do not. Neither is guilty of claiming that 'there are tables' is true, just in order to pacify the common person, only to then surreptitiously deny that there are tables under their breath. That would make their views far more radical, indeed, it would leave them open to charges of patent contradiction. However, both views are seemingly committed to something which is not a million miles away. Both views, whilst accepting the truth of 'there are tables', are committed to denying the truth of a related statement which is, although not exactly the same, very similar indeed. (This related statement can be expressed in any of those ways mentioned above, e.g. 'there really are tables', 'tables have real being' or 'tables are genuine denizens of reality', etc.). This fact saves them from contradiction but drives them far from common sense. The commonsense view of the world is not that complex. For Terry, there is simply no difference between there being tables and there really being tables. 
As a result, I would argue, not only do these two particular strategies fail to reconcile radical ontology with the truths of common sense, but any such strategy is destined to fail in that ambition. It doesn't matter how you do it, it doesn't matter how intricate your semantic manoeuvres may be, if your view involves the claim that ordinary utterances of 'there are $F s^{\prime}$ are true, yet at the same time maintains that there aren't really any Fs, then it will always conflict with common sense. For common sense does not merely maintain that there are tables' is true, but it maintains that the reason it is true is that there really are tables.

\section{§4. Objections}

I doubt that my opponents would be much impressed with my remarks thus far. Indeed, I suspect that they may well accuse me of misrepresenting, or even misunderstanding, their positions. Perhaps I have. But I should like to say a little more in order to pre-empt this response, and to explain why I think I have understood properly, and why my argument still goes through.

Let us return to our hypothetical layperson: Terry. ${ }^{17}$ My objection was based on the claim that Terry would be bewildered, and rightly so, when told that 'there are tables' is true, even though there aren't actually any tables. The thought is that this kind of suggestion conflicts with common sense at least as much as, and perhaps more than, the straightforward denial of tables. However, I suspect that the proponents of the strategies I am considering may think I am mis-representing things. For in an ordinary conversation, in ordinary English, with an ordinary layperson (if there is such a thing), I believe that my opponents might say not only that 'there are tables' is true, but that there actually are tables.

The reason for this is that both strategies I am considering are accompanied by a further claim to the effect that ordinary day-to-day discussions - what you might call, 'commonsense discussions' - are importantly different in certain respects from the technical discussions had by philosophers in that much vaunted place, the ontology room. This difference, I think they may say, will be enough to overcome my objection, for when in ordinary discussion with Terry, they would not be required to deny the existence of tables at all. When engaging with Terry, they can truly and genuinely agree that there really are tables. It is only when involved in technical philosophical discussion that they need deny such things. Cameron and Horgan

${ }^{17}$ I don't much like the term, 'layperson', but I have nothing better. I find it preferable to talking of 'the folk', which is the term one sometimes sees in the literature, but feel free to substitute in whichever terminology you see fit. 
\& Potrč have slightly different ways of formulating this line of thought, so although I think they amount to much the same thing, I will deal with them individually.

Horgan \& Potrč claim that our communications are governed by certain semantic standards, but that these standards can change according to context (Horgan \& Potrč, 2000; 2006; 2008). In ordinary parlance the standards are fairly loose, such that truth is often a matter of indirect correspondence with reality. With such standards in place, it can be perfectly true and correct to assert the existence of tables, even if the correct ontology does not actually include such things (or, to use their terminology, even if tables are 'not genuine denizens of reality') (Horgan \& Potrč, 2000, p.253). Occasionally, however, our discussions are governed by stricter standards, such that truth is a matter of direct correspondence with reality. Under these strict standards, referring terms must actually refer, thus asserting the existence of tables would ontologically commit one to such things. With this distinction in place, they claim that it is only in context of formal philosophical discussion, i.e. in the ontology room, that such strict standards are in place. Therefore, when in conversation with Terry, one would not have to concede that there aren't really any tables. No such confusing caveat needs to be added, because given the semantic standards in play, which are governed by the context of the discussion, there really are tables.

In response, I concede that semantic standards clearly differ from one context to the next. Moreover, it is also quite plausible that in the majority of ordinary contexts, the semantic standards in play are somewhat looser than they could be. This is what allows us to enjoy the odd metaphor or exaggeration, or to discuss the content of fictional stories, without having to explicitly state that we are doing so. Crucially, however, people are ordinarily well aware that these loose semantic standards are in play, even though they are not usually made explicit. The difficulty emerges when one claims that certain loose semantic standards are in play, in the majority of ordinary thought and talk, yet that the vast majority of people are not aware of it, even implicitly. Let me illustrate with some examples.

Suppose, at a dinner party, a debate was sparked about the address of Sherlock Holmes. One could quite easily imagine someone forcefully asserting, 'Holmes lives at 221b Baker Street, and that is a fact!' Now, if you were so inclined, you could point out to this person that what they had said was literally false. 'Go to 221 b Baker Street and see for yourself,' you could say. In such a case your fellow dinner guests may well grudgingly accept what you had said. ${ }^{18}$ This is because people are well aware that the semantic standards in play entail that they are discussing the content of a fictional story, and not discussing the actual inhabitants of $221 \mathrm{~b}$ Baker Street. ${ }^{19}$ But this rarely needs to be made explicit, because human beings are generally

${ }^{18}$ They may also scratch you off the list for their next party.

${ }^{19}$ Of course, there are no actual inhabitants of $221 \mathrm{~b}$ Baker Street, because there is no such address. 
very good at recognising the contexts in which their discussions take place. We don't usually have to prefix every claim we make about Sherlock Holmes with, 'according to the fictional stories by Conan Doyle...'. You don't have to explicitly tell everyone when you employ a metaphor, make a deliberately gross exaggeration, or crack a joke. People are well aware what kind of semantic standards are ordinarily in play. Indeed, part of what it is to have common sense plausibly involves the ability to detect such things. This is why your pedantic observation above about Holmes's address would be so frustrating, for it deliberately ignores the contextual standards which should be obvious for all to see. Indeed, one might reasonably counter your remark by saying, 'oh, come on, use your common sense'.

But the case is markedly different with the claim that Horgan \& Potrč are making. For ordinary people are clearly not aware that these types of semantic standards are in play in dayto-day conversation. Suppose that the dinner party debate moved on to the particular style of hat preferred by Sherlock Holmes, and you chimed in with the claim that if we were to be absolutely strict about things, we should say that Holmes didn't actually wear any style of hat, because hats do not, speaking strictly, exist. This remark would be met with an entirely different response to your previous one. You would not be branded a pedant, but a lunatic. ${ }^{20}$ It would not do for you to simply point out the loose semantic standards in play, as it would have done in the previous case. Your fellow guests would not grudgingly accept that, when talking of hats, they were only describing the world indirectly. Rather, they are likely to say you were speaking nonsense. Of course there are hats, they would surely protest, even when we are speaking absolutely strictly. ${ }^{21}$

My point is this. Horgan \& Potrč's strategy of invoking different semantic standards in different contexts may well do the job they want. If you simply stipulate the different standards which are in play in different contexts, then you can successfully get the result that certain claims come out true in one context and false in another. This allows them to say that it is true in ordinary contexts that tables exist, yet false in the ontology room. But one cannot claim this strategy to concord with common sense unless the semantic standards stipulated are themselves recognised by common sense. And in this case they are clearly not. Common sense does recognise shifts in semantic standards, as the above examples show. Sometimes we speak loosely or indirectly - such as when we discuss fiction, joke, or employ metaphor but we are well aware when we do so. But at other times we speak strictly and directly, when we want to say things how they are. Ordinary descriptions of our surroundings - when we assert how many biscuits are in the tin, for instance - clearly fall into the latter camp. We do

\footnotetext{
${ }^{20}$ By this stage, an invitation to the next party would be well and truly off the cards.

${ }^{21}$ A similar point to this has been made by Korman (2008) in opposition to David Lewis's claim that in ordinary thought and talk we restrict the domain of our quantifiers such that they exclude arbitrary mereological fusions.
} 
not think we speak loosely or indirectly when we say the Taj Mahal exists, or that there are ten biscuits in the tin, in the way that we do when we say Sherlock lives on Baker Street or that the winger was fast as lightning. To suggest that such loose and indirect semantic standards are in play for the vast majority of our ordinary thought and talk, which is what Horgan \& Potrč's claim amounts to, is evidently at odds with what ordinary people ordinarily believe, and thus runs completely counter to common sense.

Cameron makes a similar type of move to that of Horgan \& Potrč but fleshes it out in quite a different way. He endorses a view that has attracted a fair bit of attention in recent years, to the effect that English is not well-suited to describe the fundamental structure of reality. ${ }^{22}$ The quantifiers and predicates of English do not, to use the much-used Platonic metaphor, carve the beast of reality at its joints. This is not to say that we cannot give correct (and of course incorrect) descriptions of the world in English - we can. It is just that these descriptions do not characterise the world as it fundamentally is.

To illustrate, consider an example. I could introduce a new predicate, 'pengatonne', which applies only to those things which are either penguins or which have mass of more than one tonne. Having stipulated this, I would then be correct to assert that there are (at least) eight pengatonnes in orbit around our Sun, but I would be incorrect to assert that I am married to a pengatonne. Cameron's view would have it that I speak truly when I make these assertions (or falsely, in the latter case), but simply that I am not describing the world as it fundamentally is. A correct and perspicacious account of the fundamental nature of reality would not include reference to pengatonnes.

We could, however, imagine a language perfectly suited to describing the fundamental nature of reality; a language in which the quantifiers and predicates carve at the joints. Let us follow recent convention and call such a language, 'Ontologese' ${ }^{23}$ Let me also follow Cameron's lead and use bold type to indicate when I am aiming to make a claim in Ontologese rather than in English (Cameron, 2008a, p.300). According to Cameron, then, whilst it is true that there are tables, it is not true that there are tables.

${ }^{22}$ Ted Sider (2011) has defended this kind of view at length.

${ }^{23}$ This is a much-used term in metaphysics nowadays, but I believe it was Sider (2004) who actually coined it. 
Once armed with this distinction, there is a possible line of response to my objection. For ordinary people like Terry speak English, not Ontologese. My original contention was that Terry would be rightly baffled if he was told that 'there are tables' is true, although there aren't really any tables. But Cameron may well respond that he would never make such a claim. When speaking English, not only is 'there are tables' true, but there really are tables! Thus one would not be required to make any confusing caveats to Terry at all. Of course, it is not true that there are tables, but that is a sentence of Ontologese: a language which Terry, presumably, does not understand.

So there we have it: there is no clash with what Terry believes after all. Common sense saved! As Cameron says: 'This view does not go against common sense because common sense demands only that there are statues; it does not demand that there are statues' (Cameron, 2008a, p.301). Moreover, he makes the further claim that existence claims in Ontologese are not 'part of the corpus of our common-sense beliefs', thus it cannot be counter to common sense to claim there are no tables (or statues, etc.). It would conflict with common sense to deny that there are tables, but there is no pressure to do that, because there are tables.

I must confess I am suspicious about this approach for a number of reasons, but what I want to stress here is that there still remain good reasons to believe that this kind of view is sharply at odds with what we ordinarily believe. Suppose, for instance, that Terry managed to sneak into the ontology room only to overhear a couple of philosophers openly asserting that there are no tables. He might reasonably demand an explanation. Now if these philosophers assured him they were not speaking English, but another language entirely (i.e. Ontologese), I contend that Terry might still not be satisfied. He would surely be justified in asking the further question: what does the Ontologese sentence, 'there are no tables', actually mean?

This would put the two philosophers in a tricky situation, for it is not at all easy to explain what such a sentence means. One cannot simply translate a sentence of Ontologese into English in the way one can translate English into French. The basic apparatus of the languages - e.g. the quantifiers - are fundamentally different, so translation is a very difficult affair. But Terry is waiting; an answer must be forthcoming. These philosophers cannot dismissively wave him away, condescendingly insisting that he just wouldn't understand (especially not if they want to maintain that their view accommodates common sense and ordinary belief).

But perhaps this is too hasty? Perhaps, at this point, one might think that the two philosophers are in fact perfectly entitled to dismissively wave Terry away. They are having a technical discussion, after all, thus one should not expect those not versed in the discipline to understand what is being said. Terry might be equally baffled if he were to eavesdrop on 
conversations in the quantum mechanics room, for instance, but that does not entitle him to demand some clear and easy explanation of what is being discussed. ${ }^{24}$

I think, however, that this response might be a little off the mark, and that the analogy with the quantum mechanics room is not an entirely fair one, for two reasons. First, the sentence which Terry overhears in the ontology room (i.e. "there are no tables") is one which sounds very much like an ordinary sentence of English; a sentence which Terry thinks he understands perfectly well. This is not the case in the quantum mechanics room. If Terry overhears two physicists discussing 'density matrices', 'wave-particle duality', 'quantum entanglement', or what have you, he would be well aware that these are technical terms with which he is not, let us presume, familiar.

Secondly, and more importantly, however, there is a clear sense in which the discussion Terry overhears in the ontology room offends and conflicts with his ordinary beliefs. Terry thinks there are tables and, moreover, these philosophers were only a moment ago happy to accept that it is true that there are tables. Yet here they are in the ontology room, asserting something which appears to directly contradict their earlier remarks. Again, the case is clearly not the same in the quantum room. The physicists' assertions about various quantum phenomena presumably do not conflict with any of Terry's ordinary beliefs, nor would they appear to conflict with anything the physicists had previously said. Rather, Terry would simply recognise immediately that this was a technical discussion on a subject of which he knows nothing.

It seems perfectly reasonable to suppose, therefore, that Terry would want an explanation of the philosophers' assertion, and indeed that he would be prima facie justified in demanding one (whilst this would clearly not be the case in the quantum room). The philosophers could, of course, wave him away insisting that they were having a technical discussion in a language which he doesn't understand, but they could not at the same time insist that their views were consistent with common sense. Terry would presumably think that they were completely lacking in common sense. One minute they say there are tables, the next minute they say there aren't!

Let us suppose, then, that the two philosophers were not so dismissive but were in fact more accommodating. They understood Terry's confusion, and they recognised that, on the surface at least, it may seem as though they were contradicting themselves. They want to allay Terry's confusion and put his mind at rest. What, then, could they say?

It strikes me that these philosophers would have no option but to revert to those rather grand yet mysterious turns of phrase that we encountered earlier on. They may say, for instance,

${ }^{24}$ I thank an anonymous referee for suggesting this objection. 
that unlike English, their language is one that, 'limns the fundamental structure of reality', or describes the 'ultimate furniture of the world' or the 'genuine denizens of reality', or indeed, that 'carves reality at its joints'. Perhaps they could say that the objects quantified over in Ontologese have 'real being' as opposed to many of those things quantified over in English. It is at this point where my suspicions begin to creep in, for when grandiose phrases like these are offered up in place of what I would call clear and lucid explanations, one can't help but wonder whether the wool is being pulled over one's eyes.

Nevertheless, one thing is clear: Terry is unlikely to be satisfied. For no matter what prose it is dressed up in, Terry is being informed that when he describes the world using his language, he is not actually describing the way it really is. But Terry would balk at such a claim. We do not ordinarily believe that we describe the world in some indirect or misleading way. ${ }^{25} \mathrm{We}$ ordinarily believe that we say it like it is. When we say that there is a table in the room, or that there are eight planets in the solar system, or that there are three cars parked on the street, we mean exactly that. That there is a table in the room, and there are eight planets in the solar system and three cars on the street. But we don't merely mean these things in some mysteriously obscure way; we mean them directly. We mean them absolutely. We believe that what we are saying accurately describes the way things really are.

To surmise, both views currently under consideration make novel claims about the way language relates to the world. They flesh it out in different and illuminating ways, but both amount to the same basic claim: the way we ordinarily think and talk does not tally up directly with the way things really are. There is, according to these views, a fundamental cleavage between the way we ordinarily describe the world and the way the world actually is. Unbeknownst to most of us, we are forever condemned to metaphor. We can utter truths about the world, but only obliquely, in some kind of roundabout and opaque way. We can describe the world, and we can do so correctly, but we do not describe it as it really is.

My claim is that this view itself is radically at odds with common sense, for common sense takes a view on how language relates to the world. When Terry asserts that 'there are ten biscuits in the biscuit tin', he does not merely believe that he is uttering some oblique truth, but he believes something about the world. He believes that there are some actual things in front of him (i.e. some biscuits and a tin), and it is the very existence of these things that makes his assertion true.

Of course, I can already imagine the forthcoming response. 'But Terry is right - there really are ten biscuits in the tin! (given the semantic standards in play, or the meanings of his quantifiers)'. But I hope to have shown that this response will not wash. Terry would not

${ }^{25}$ Unless, of course, we are employing metaphor or some other kind of stylistic device. But, as mentioned earlier, we are usually well aware when we are doing this. 
accept these non-standard semantic standards or quantifier meanings once they are brought to his attention. They are being imposed on him against his will. Of course, it may be true that these loose semantic standards are in play, or that English really does fail to carve at nature's joints. I am not claiming these suggestions to be false, but simply maintaining that, in light of the above remarks, they very much contravene what we ordinarily believe, thus could not for one moment be said to concord with common sense.

\section{§5. Conclusions}

If what I have said above is correct, then two important conclusions can be drawn. The first is that what I have called truth-salvaging strategies (i.e. strategies which claim that assertions of the form, 'there are Fs' can be true, even if there are not really any Fs) will always, in principle, conflict with common sense. This is because common sense takes a view not only on what the truths are, but on why they are true. Conforming with common sense requires more than merely paying lip-service to the things we ordinarily believe and say. It requires an ontological picture of the world that accords with how those beliefs state the world to be. Truth-salvaging strategies succeed in the former but fail in the latter.

This counts against these strategies in a fairly significant way, for one of the major motivations for them in the first place is that they purport to salvage common sense. I should stress once more, however, that this does not mean such strategies are false or should be abandoned. There may be very good independent reasons for endorsing them. ${ }^{26}$ But one must not think that these strategies offer an easy response to the 'common sense objection' that is often levelled against radical philosophical views.

Secondly, this means that those who are attracted to radical ontological views must take the counter-intuitiveness of their conclusions squarely on the chin. No amount of linguistic chicanery or metasemantic innovation will be sufficient to salvage common sense, for common sense clearly has a rather straightforward understanding of how language relates to the world.

How significant one finds these conclusions will really depend on how much weight one places on the dictates of common sense. My own view on the matter is very much on the Parmenidean side of things - I see little reason to bow to the pressures of common sense - but I am aware that this goes against the norm. The standard view seems to be that philosophy simply doesn't have the authority to overrule our commonsense beliefs. I could have appealed

${ }^{26}$ Indeed, Cameron in particular has given a number of quite compelling independent reasons in support of his view. See Cameron (2008b) 
to any number of philosophers to reinforce the point, but Kit Fine puts it quite succinctly: 'in this age of post-Moorean modesty, many of us are inclined to doubt that philosophy is in possession of arguments that might genuinely serve to undermine what we ordinarily believe' (Fine, 2001, p.2).

For those who subscribe to this line of thought, the conclusions reached in this paper will be of some significance. For the conjunction of both views (i.e. the conclusion of this paper and the sentiment expressed by Kit Fine) would seem to effectively rule out radical ontological views tout court.

\section{§6. References}

Bertrand Russell, The Philosophy of Logical Atomism, (London: Routledge, 1972)

Cian Dorr, 'There Are No Abstract Objects' in Sider, T., Hawthorne, J. \& Zimmerman, D. (eds.) Contemporary Debates in Metaphysics, (Oxford: Blackwell, 2008)

Cian Dorr, 'What we disagree about when we disagree about ontology', in Kalderon, M. (ed.) Fictionalism in Metaphysics, (Oxford: Clarendon, 2005), pp.234-286

Daniel Korman, 'Unrestricted Composition and Restricted Quantification', Philosophical Studies, 140, 3, (2008) pp.319-334

David Armstrong, Truth and Truthmakers, (Cambridge: CUP, 2004)

David Armstrong, Universals: An Opinionated Introduction, (Boulder, Colorado: Westview Press, 1989)

David Chalmers, 'Ontological Anti-Realism' in Chalmers, D., Manley, D., \& Wasserman, R. (eds.) Metametaphysics, (Oxford: OUP, 2009), pp.77-129

David M. Cornell, 'Taking Monism Seriously', Philosophical Studies, 173, (2016), pp.2397-2415

David M. Cornell, 'Mereological Nihilism and the Problem of Emergence', American Philosophical Quarterly, 54, 1, (2017), pp.77-87

Helen Beebee \& Julian Dodd (eds.), Truthmakers: The Contemporary Debate, (Oxford: OUP, 2005)

John Heil, From an Ontological Point of View, (Oxford: OUP, 2003)

John Heil, The Universe As We Find It, (Oxford: OUP, 2012) 
John Keller, 'Paraphrase, Semantics, and Ontology' in Bennett, K. and Zimmerman, D. (eds.) Oxford Studies in Metaphysics, vol.9, (Oxford: OUP, 2015), pp.89-124

Jonathan Schaffer, 'On What Grounds What' in Chalmers, D., Manley, D., \& Wasserman, R. (eds.) Metametaphysics, (Oxford: OUP, 2009), pp.347-383

Kit Fine, 'A Question of Realism', Philosophers' Imprint, 1, (2001) pp.1-30

Mark Siderits, 'Persons and Selves in Buddhist Philosophy', in LoLordo, A. (ed.) Persons: A History, (Oxford: OUP, 2019), pp. 301-325

Peter Unger, 'I Do Not Exist', in MacDonald, G. F. (ed.) Perception and Identity, (London: Palgrave, 1979)

Peter van Inwagen, Material Beings, (Ithaca, NY: Cornell University Press, 1990)

Rene Descartes, A Discourse on Method, (London: J. M. Dent \& Sons, 1934)

Ross Cameron, 'How to have a radically minimal ontology', Philosophical Studies, 151, (2010a) pp.249-264

Ross Cameron, 'Quantification, Naturalness and Ontology' in Hazlett, A. (ed.) New Waves in Metaphysics, (London: Palgrave MacMillan, 2010b), pp.8-26

Ross Cameron, 'There are no things that are musical works', British Journal of Aesthetics, 48, 3, (2008a) pp.295-314

Ross Cameron, 'Truthmakers and Ontological Commitment', Philosophical Studies, 140, (2008b) pp.1-18

Terry Horgan \& Matjaz Potrč, 'Abundant Truth in an Austere World', in Greenough, P. \& Lynch, M. P. (eds.) Truth and Realism, (Oxford: OUP, 2006), pp.137-167

Terry Horgan \& Matjaz Potrč, 'Blobjectivism and Indirect Correspondence', Facta Philosophica, 2, (2000) pp.249-270

Terry Horgan \& Matjaz Potrč, Austere Realism: Contextual Semantics Meets Minimal Ontology, (Cambridge, Mass.: MIT Press, 2008)

Theodore Sider, 'Against Parthood', in Bennett, K \& Zimmerman, D. (eds.) Oxford Studies in Metaphysics, vol. 8, (Oxford: OUP, 2013), pp.237-293

Theodore Sider, 'Replies to Gallois, Hirsch, and Markosian', Philosophy and Phenomenological Research, 68, 3, (2004) pp.674-687 
Theodore Sider, Writing the Book of the World, (Oxford: OUP, 2011)

Trenton Merricks, Objects and Persons, (Oxford: Clarendon, 2001)

David M. Cornell (dmcornell@uclan.ac.uk) is a lecturer in philosophy at the University of Central Lancashire. 